\title{
Vacinação contra a febre amarela nos Estados da Região Norte do Brasil: uma análise entre 2010 e 2019
}

\author{
Yellow fever vaccination in the Northern States of Brazil: an analysis between 2010 and \\ 2019
}
Vacunación contra la fiebre amarilla en los Estados del Norte de Brasil: un análisis entre 2010 y 2019

Amanda Zahlouth Serique Gato ${ }^{1}$, Isabella Edwiges Figueiredo lunes Costa ${ }^{1}$, Isabella Rocha de Campos $^{1}$, Joaquim Pedro Junior ${ }^{1}$, Thor Guilhon Freitas de Oliveira ${ }^{1}$, Wilhames Rodrigues da Silva Lima $^{1 *}$, Maria Helena Rodrigues de Mendonça1', Sérgio Beltrão de Andrade Lima'.

\section{RESUMO}

Objetivo: Descrever e analisar a situação vacinal da febre amarela nos Estados da Região Norte do Brasil, sendo eles Tocantins, Pará, Amapá, Roraima, Amazonas, Acre, e Rondônia, durante o período de 2010 a 2019. Métodos: Trata-se um estudo observacional do tipo transversal, de caráter descritivo e analítico. Os dados foram obtidos a partir dos registros públicos do site DATASUS. Os dados obtidos foram analisados por estatística descritiva com auxílio do software Statistica 7.0. O teste Tukey foi aplicado em caso de significância estatística entre as médias $(p<0,05)$. Resultados: Praticamente todos os Estados apresentaram queda no número de doses aplicadas de vacina conta febre amarela nos últimos dois anos, com exceção de Roraima, que demonstrou um pequeno aumento no último ano analisado, 2019. Os municípios que mais vacinaram foram: São Francisco do Guaporé (RO); Plácido de Castro (AC); Careiro da Várzea (AM); Caroebe (RR); Piçarra (PA); Cutias (AP); e Talismã (TO). Conclusão: Este estudo sinalizou a queda na vacinação contra a febre amarela em vários Estados da Região Norte no período analisado, bem como a necessidade de estudos epidemiológicos sobre o assunto, assim, visando a intensificação das medidas de prevenção voltadas para a vacinação da população como um todo.

Palavras-chave: Cobertura vacinal, Imunização, Epidemiologia descritiva.

\section{ABSTRACT}

Objective: Describe and analyze the yellow fever vaccination situation in the States of the Northern Region of Brazil, namely Tocantins, Pará, Amapá, Roraima, Amazonas, Acre, and Rondônia, during the period from 2010 to 2019. Methods: This is an observational, cross-sectional, descriptive and analytical study. Data were obtained from public records on the DATASUS website. The data obtained were analyzed using descriptive statistics using the Statistica 7.0 software. The Tukey test was applied in case of statistical significance between the means $(p<0.05)$. Results: Practically all states showed a drop in the number of doses of yellow fever vaccine applied in the last two years, with the exception of Roraima, which showed a small increase in the last year analyzed, 2019. The municipalities that most vaccinated were: São Francisco do Guaporé (RO); Plácido de Castro (AC); Careiro da Várzea (AM); Caroebe (RR); Piçarra (PA); Cutias (AP); e Talismã (TO). Conclusion: This study signaled the drop in yellow fever vaccination in several states in the North Region during the period analyzed, as well as the need for epidemiological studies on the subject, thus aiming to intensify prevention measures aimed at vaccinating the population in general.

Keywords: Vaccination coverage, Immunization, Descriptive epidemiology.

\section{RESUMEN}

Objetivo: Describir y analizar la situación de vacunación contra la fiebre amarilla en los Estados del Norte de Brasil, a saber, Tocantins, Pará, Amapá, Roraima, Amazonas, Acre y Rondônia, entre 2010 a 2019. Métodos: Este es un estudio observacional, transversal, descriptivo y analítico. Datos obtenidos de registros públicos en el sitio web de DATASUS. Los datos se analizaron mediante estadística descriptiva utilizando el software Statistica 7.0. Se aplicó la prueba de Tukey en caso de significancia estadística entre las medias $(\mathrm{p}<0.05)$. Resultados: Prácticamente todos los Estados mostraron una caída en el número de dosis de vacuna contra la fiebre amarilla aplicadas en los últimos dos años, a excepción de Roraima, que mostró un pequeño aumento en el último año analizado. Los municipios que más vacunaron fueron: São Francisco do Guaporé (RO); Plácido de Castro (AC); Careiro da Várzea (AM); Caroebe (RR); Piçarra (PA); Cutias (AP); e Talismã (TO). Conclusión: Este estudio señaló la caída de la vacunación contra la fiebre amarilla en varios Estados de la Región Norte, así como la necesidad de realizar estudios epidemiológicos sobre el tema, con el objetivo de intensificar las medidas de prevención dirigidas a vacunar a la población en general.

Palabras clave: Cobertura de vacunación, Inmunización, Epidemiología descriptiva.

${ }^{1}$ Centro Universitário Metropolitano da Amazônia (UNIFAMAZ), Belém - PA. *E-mail: wilhamesrodrigues@hotmail.com 


\section{INTRODUÇÃO}

A Febre Amarela (FA) é causada por um vírus do gênero flavivírus (família Flaviviridae). É uma doença de caráter infeccioso e agudo, não contagiosa e com alta letalidade; com apenas um sorotipo catalogado; além disso, possui um genoma constituído de RNA de fita simples e não segmentado (BRASIL, 2018; COUTOLIMA D, et al., 2017; FOCACCIA R e VERONESI R, 2015). Está incluído nos arbovírus, os quais são transmitidos para os vertebrados por meio da picada de artrópodes (TARTAGLIA TT e PACCA CC, 2019).

As características clínicas da febre amarílica são muito abrangentes, as quais podem ocorrer desde formas subclínicas, formas leves assintomáticas, até formas graves com alta mortalidade (BRASIL, 2018). Apresenta sintomas como febre alta, calafrios, cefaleia, dorsalgia, mialgia, prostração, náuseas, vômitos, hepatite com icterícia, insuficiência renal, hemorragia, choque e morte em 20-60\% dos casos (BRASIL, 2018; MONATH TP e VASCONCELOS PFC, 2015).

Epidemiologicamente, a FA possui 2 ciclos, o urbano e o silvestre, porém eles não possuem nem uma diferença etiológica, clínica, imunológica ou fisiopatológica. No ciclo silvestre os principais hospedeiros do vírus são os primatas, ao passo que no ciclo urbano o homem é o único hospedeiro com importância epidemiológica (MONATH TP e VASCONCELOS PFC, 2015). Quanto aos vetores, na zona urbana se tem o Aedes aegypti, e o homem contaminado opera como reservatório; em contrapartida, no âmbito rural os vetores, no Brasil, são os mosquitos do gênero Haemagogus e Sabethes (BRASIL, 2018).

As florestas do Norte da América do Sul têm sido consideradas um território-chave para a manutenção e emergência das linhagens do vírus da FA (MIR D, et al., 2017). No Brasil, o vírus é enzoótico/endêmico na região Amazônica, que ocupa toda a região Norte, de onde às vezes se expande em direção às regiões Centro-Oeste, Sul e Sudeste, causando eventos epizoóticos isolados e infecções humanas até epidemias graves de origem silvestre (POSSAS C, et al., 2018).

A disseminação da FA em 2008 e 2009 no Brasil foi impressionante. Os primeiros casos foram notificados na região Norte, Estado do Pará (municípios de Afuá e Breves), no início de 2008 e, posteriormente, nos Estados de Tocantins e Goiás. Em 2009, uma grande onda epizoótica e epidêmica ocorreu nos Estados de Goiás e Mato Grosso do Sul (região Central), e atingiu o extremo Sul até o Rio Grande do Sul. Um nível mais baixo de atividade de FA foi relatado nos anos seguintes a este episódio (MONATH TP e VASCONCELOS PFC, 2015). No final de 2016 o Brasil enfrentou um surto sem precedentes de FA silvestre, o qual afetou principalmente a região Sudeste (FIGUEIREDO PO, et al., 2018). Apesar de existir a vacina, esses recentes surtos dão sinais de uma possível reemergência da doença em locais que antes eram livres da circulação do vírus.

Desde a década de 1940, a existência da vacina de dose única tem ajudado a controlar e reduzir os casos de FA de forma substancial (BARRETT ADT, 2016). Produzida a partir do vírus atenuado, a vacina 17D proporciona proteção por, no mínimo, dez anos contra a febre amarílica (WORLD HEALTH ORGANIZATION (WHO), 2019). Desse modo, as campanhas de vacinação são extremamente importantes para atingir 0 máximo de imunização possível na população. Embora a vacina seja altamente eficaz contra $F A$, a qual já está disponível há quase um século, como mostram os dados históricos, surtos da doença ainda ocorrem.

Em países em desenvolvimento, como o Brasil, a baixa cobertura vacinal pode se dar por motivos econômicos e até mesmo por dificuldades intrínsecas de acesso à população que vive em áreas silvestres, além de fatores sociais ou relacionados à saúde (MCDONALD NE, 2015; ARAÚJO MCG, et al., 2020). Nesse contexto, dentre as cinco regiões brasileiras, o Norte possui a menor cobertura vacinal (OLIVEIRA GS, et al., 2020).

Portanto, esta pesquisa objetiva descrever e analisar a situação vacinal da febre amarela nos Estados da região Norte do Brasil, sendo eles: Tocantins (TO), Pará (PA), Amapá (AP), Roraima (RR), Amazonas (AM), Acre (AC) e Rondônia (RO); durante o período de 2010 a 2019.

\section{MÉTODOS}

O trabalho é caracterizado como estudo observacional do tipo transversal, de caráter descritivo e analítico. Foi realizado o levantamento de dados quantitativos referente a doses aplicadas e cobertura vacinal usando como base os registros públicos junto ao site departamento de informática do Sistema Único de Saúde do Brasil (DATASUS) nos Estados da Região Norte do Brasil. 
Os dados coletados foram transferidos para a ferramenta Microsoft Excel 2016 na forma de tabela. Após o tratamento dos dados, foram selecionadas as cinco cidades com maior cobertura vacinal e as cinco cidades com a menor cobertura vacinal em cada um dos Estados analisados.

As análises estatísticas foram realizadas com o auxílio do software Statistica 7.0. Análises de variância (ANOVA, $\alpha=5 \%$ ) one way foram realizadas para verificar as diferenças médias entre as variáveis dependentes (local e ano) e as variáveis independentes (cobertura vacinal e número de doses aplicadas). O teste Tukey foi aplicado sempre que os resultados apresentaram médias estatisticamente significativas.

\section{RESULTADOS}

A cobertura vacinal apresentou resultado estatisticamente significativo $(p<0,05)$, e as maiores médias corresponderam ao Estado de Rondônia, cuja maior média se deu no ano de 2016. Por outro lado, Rondônia, Roraima e Tocantins apresentaram queda nos últimos dois anos analisados (Figura 1).

Figura 1 - Resultados de ANOVA ( $\alpha=5 \%$ ) para cobertura vacinal contra febre amarela aplicadas nos Estados da região Norte entre 2010 e 2019.

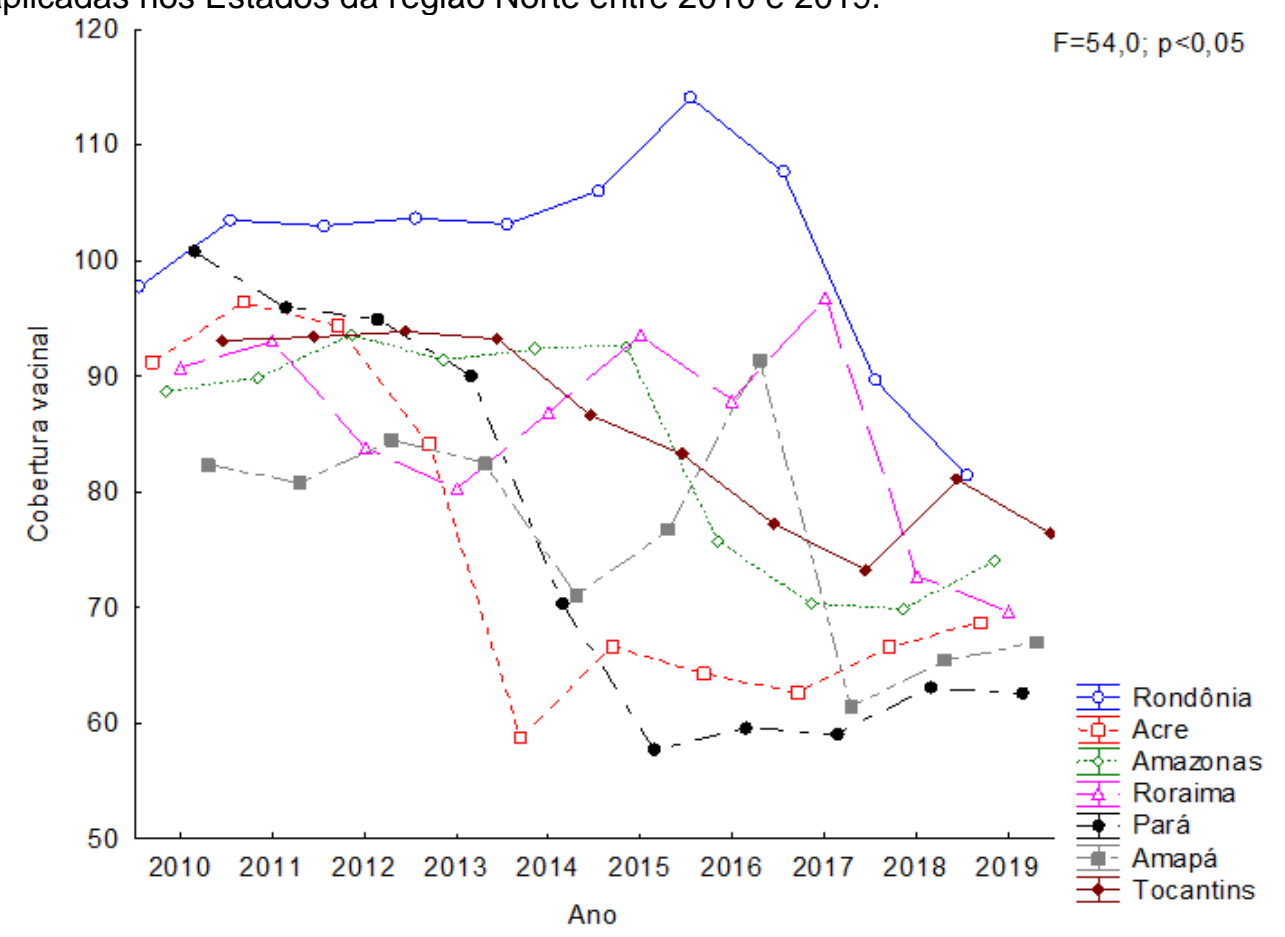

Fonte: Gato AZS, et al., 2021.

O teste Tukey mostrou a diferença entre o tamanho das amostras, onde o tratamento a (Rondônia) é superior e diferente significativamente dos demais, enquanto que os tratamentos b (Acre, Pará e Amapá) e c (Amazonas, Tocantins e Roraima) não diferem entre si (Tabela 1).

Tabela 1 - Resultados do teste Tukey para a cobertura vacinal contra febre amarela nos Estados da região Norte entre 2010 e 2019.

\begin{tabular}{ccc}
\hline Grupo Tukey $^{*}$ & Tratamentos (Estados) & Médias \\
\hline a & Rondônia & 101,00 \\
b & Acre & 75,39 \\
b & Pará & 75,43 \\
b & Amapá & 76,36 \\
c & Amazonas & 83,87 \\
c & Roraima & 85,58 \\
c & Tocantins & 85,16 \\
\hline
\end{tabular}

Legenda: *Comparação entre as médias dos tratamentos (a - Rondônia;

b - Acre/Pará/Amapá; c - Amazonas/Roraima/Tocantins).

Fonte: Gato AZS, et al., 2021. 
O número de doses aplicadas foi estatisticamente significativo entre os Estados $(p<0,05)$. O Pará se destacou com as maiores médias, exceto pelos anos de 2014 e 2015, onde sofreu queda, depois retomando com um aumento expressivo em 2017 e, novamente, sofrendo queda nos últimos dois anos analisados, mas ainda se mantendo com as maiores médias em comparação aos demais. Praticamente todos os Estados apresentaram queda no número de doses aplicadas de vacina conta FA nos últimos dois anos, com exceção de Roraima, que demonstrou um pequeno aumento no último ano analisado, 2019 (Figura 2).

Figura 2 - Resultados de ANOVA ( $\alpha=5 \%$ ) para o número de doses de vacina contra febre amarela aplicadas nos Estados da região Norte entre 2010 e 2019.

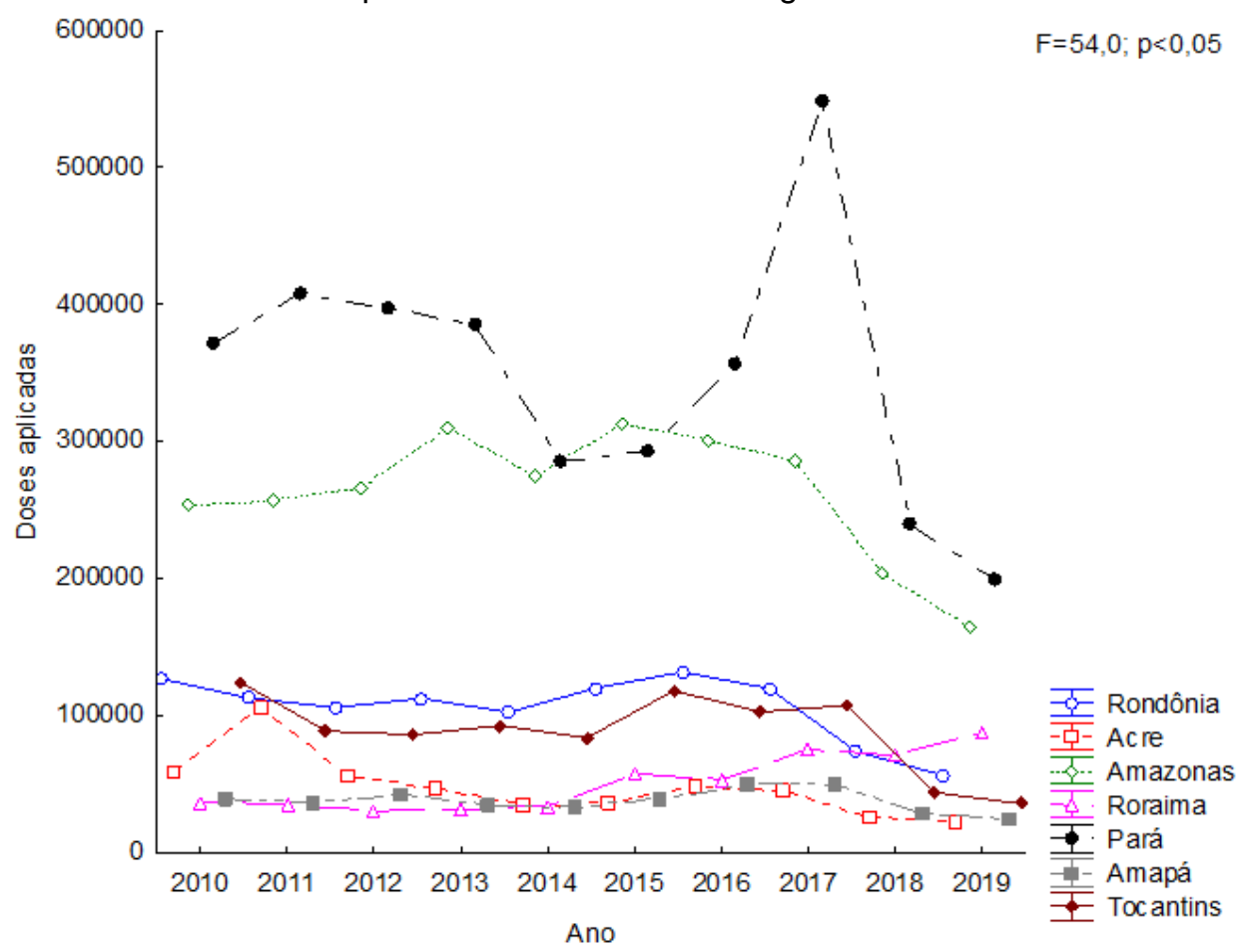

Fonte: Gato AZS, et al., 2021.

O teste Tukey, para as doses aplicadas, mostrou que o tratamento a (Pará) é superior e diferente significativamente dos demais, enquanto que os tratamentos $c$ (Rondônia, Tocantins, Roraima e Acre) não diferem entre si. O tratamento $b$ (Amazonas) difere dos demais e é o segundo melhor tratamento, ou seja, a segunda melhor média, inferior à média do Pará e superior às médias de Rondônia, Tocantins, Roraima, Acre e, especialmente, à média do Amapá, que foi a menor dentre todos os Estados (Tabela 2).

Tabela 2 - Resultados do teste Tukey para o número de doses de vacinas contra febre amarela aplicadas nos Estados da região Norte entre 2010 e 2019.

\begin{tabular}{ccc}
\hline Grupo Tukey & Tratamentos (Estados) & Médias \\
\hline a & Pará & 348920,8 \\
b & Amazonas & 263234,5 \\
c & Rondônia & 106378,9 \\
c & Tocantins & 88525,5 \\
c & Roraima & 51343,8 \\
c & Acre & 48161,8 \\
d & Amapá & 38077,9 \\
\hline
\end{tabular}

Legenda: *Comparação entre as médias dos tratamentos ( $a$ - Pará; $b$ - Amazonas; c-Rondônia/Tocantins/Roraima/Acre; d - Amapá).

Fonte: Gato AZS, et al., 2021.

A Tabela 3 mostra os cinco municípios com a maior e a menor cobertura vacinal em cada Estado. Esses resultados permitem conhecer a epidemiologia de vacinação das cidades que destacaram por seu desempenho de imunizações contra a FA ao longo da série histórica analisada. 
Tabela 3 - Municípios com a maior e menor cobertura vacinal contra febre amarela nos Estados da região Norte entre 2010 e 2019.

$$
\text { RONDÔNIA }
$$

\begin{tabular}{|c|c|c|c|c|c|c|c|c|c|c|c|}
\hline \multicolumn{12}{|c|}{ Maior cobertura vacinal } \\
\hline Município & 2010 & 2011 & 2012 & 2013 & 2014 & 2015 & 2016 & 2017 & 2018 & 2019 & Méd \\
\hline Chupinguaia & 134,91 & 200,94 & 174,53 & 176,47 & 147,46 & 130,38 & 111,39 & 336,71 & 73,20 & 68,64 & 155,46 \\
\hline São Francisco do Guaporé & 422,08 & 381,82 & 341,56 & 110,98 & 76,42 & 132,33 & 113,64 & 162,99 & 100,33 & 92,19 & 193,43 \\
\hline Teixeirópolis & 142,31 & 148,08 & 125,00 & 90,00 & 136,84 & 143,75 & 108,70 & 159,42 & 94,92 & 110,34 & 125,94 \\
\hline Corumbiara & 172,13 & 127,87 & 107,38 & 133,67 & 125,00 & 116,38 & 102,40 & 144,00 & 76,26 & 139,08 & 124,42 \\
\hline Itapuã do Oeste & 137,61 & 229,91 & 115,38 & 107,30 & 128,07 & 111,38 & 139,18 & 106,19 & 55,81 & 90,53 & 122,14 \\
\hline \multicolumn{12}{|c|}{ Menor cobertura vacinal } \\
\hline Município & 2010 & 2011 & 2012 & 2013 & 2014 & 2015 & 2016 & 2017 & 2018 & 2019 & Méd \\
\hline Campo novo de Rondonia & 79,49 & 47,69 & 61,54 & 53,89 & 27,44 & 74,32 & 27,62 & 137,57 & 55,56 & 63,79 & 62,891 \\
\hline Espigão dl'Oeste & 78,64 & 20,98 & 83,74 & 77,22 & 101,26 & 103,89 & 106,87 & 104,65 & 88,89 & 76,17 & 84,231 \\
\hline Guajara-Mirim & 84,64 & 87,33 & 100,56 & 108,16 & 78,83 & 104,71 & 112,83 & 53,48 & 68,10 & 69,12 & 86,776 \\
\hline Mirante da Serra & 71,85 & 89,50 & 78,15 & 94,33 & 100,68 & 104,10 & 114,60 & 129,20 & 60,81 & 58,97 & 90,219 \\
\hline Jaru & 74,95 & 79,96 & 80,60 & 83,22 & 92,33 & 102,52 & 101,27 & 100,23 & 76,46 & 97,87 & 88,941 \\
\hline \multicolumn{12}{|c|}{ ACRE } \\
\hline \multicolumn{12}{|c|}{ Maior cobertura vacinal } \\
\hline Município & 2010 & 2011 & 2012 & 2013 & 2014 & 2015 & 2016 & 2017 & 2018 & 2019 & Méd \\
\hline Plácido de Castro & 156,64 & 118,88 & 102,65 & 87,69 & 85,55 & 139,14 & 125,47 & 83,54 & 59,29 & 90,16 & 104,90 \\
\hline Xapuri & 134,34 & 97,64 & 113,13 & 82,62 & 82,32 & 95,58 & 73,86 & 93,46 & 76,22 & 72,46 & 92,16 \\
\hline Epitaciolandia & 103,40 & 109,43 & 106,42 & 91,29 & 56,38 & 90,91 & 80,92 & 87,40 & 98,52 & 59,45 & 88,41 \\
\hline Senador Guiomard & 133,24 & 118,99 & 161,73 & 98,87 & 50,00 & 46,68 & 46,02 & 53,32 & 55,85 & 105,32 & 87,00 \\
\hline Brasileia & 122,08 & 108,49 & 101,70 & 82,40 & 98,02 & 59,85 & 72,94 & 56,49 & 85,31 & 58,95 & 84,62 \\
\hline \multicolumn{12}{|c|}{ Menor cobertura vacinal } \\
\hline Município & 2010 & 2011 & 2012 & 2013 & 2014 & 2015 & 2016 & 2017 & 2018 & 2019 & Méd \\
\hline Assis Brasil & 49,40 & 53,27 & 58,33 & 51,55 & 23,39 & 42,86 & 53,89 & 48,19 & 65,26 & 58,47 & 50,46 \\
\hline Rodrigues Alves & 46,69 & 39,52 & 75,00 & 47,84 & 54,87 & 99,17 & 98,98 & 28,75 & 39,07 & 37,16 & 56,71 \\
\hline Porto Acre & 89,09 & 56,34 & 78,76 & 65,74 & 65,80 & 45,58 & 45,50 & 51,77 & 73,24 & 46,74 & 61,86 \\
\hline Feijó & 119,17 & 100,14 & 84,98 & 51,50 & 55,27 & 34,82 & 41,62 & 54,35 & 48,97 & 55,70 & 64,65 \\
\hline Marechal Thaumaturgo & 98,41 & 93,85 & 93,25 & 81,28 & 36,31 & 31,94 & 24,54 & 53,24 & 79,35 & 68,04 & 66,02 \\
\hline
\end{tabular}


AMAZONAS

\begin{tabular}{|c|c|c|c|c|c|c|c|c|c|c|c|}
\hline \multicolumn{12}{|c|}{ Maior cobertura vacinal } \\
\hline Município & 2010 & 2011 & 2012 & 2013 & 2014 & 2015 & 2016 & 2017 & 2018 & 2019 & Méd \\
\hline Careiro da Várzea & 170,48 & 149,52 & 114,29 & 113,00 & 214,04 & 202,94 & 58,17 & 87,98 & 107,04 & 94,94 & 131,24 \\
\hline Japura & 124,37 & 113,45 & 115,97 & 142,45 & 111,97 & 85,27 & 110,81 & 77,70 & 94,67 & 86,96 & 106,36 \\
\hline Urucara & 113,27 & 115,99 & 108,84 & 128,77 & 116,50 & 85,05 & 89,79 & 89,08 & 102,64 & 87,41 & 103,73 \\
\hline Boa vista do Ramos & 95,05 & 86,20 & 105,21 & 135,61 & 150,38 & 125,31 & 109,23 & 80,92 & 90,06 & 78,68 & 105,67 \\
\hline Manaquiri & 150,31 & 138,65 & 143,56 & 123,89 & 90,80 & 73,09 & 105,15 & 93,99 & 101,58 & 67,00 & 108,80 \\
\hline \multicolumn{12}{|c|}{ Menor cobertura vacinal } \\
\hline Município & 2010 & 2011 & 2012 & 2013 & 2014 & 2015 & 2016 & 2017 & 2018 & 2019 & Méd \\
\hline Novo Aripuana & 57,83 & 38,89 & 52,78 & 63,95 & 61,44 & 62,46 & 58,77 & 15,79 & 41,15 & 58,37 & 51,14 \\
\hline Barcelos & 66,55 & 54,39 & 73,65 & 98,65 & 36,25 & 25,26 & 49,75 & 66,41 & 51,41 & 41,41 & 56,37 \\
\hline Ipixuna & 47,12 & 58,21 & 37,53 & 58,62 & 66,74 & 43,78 & 49,36 & 55,73 & 64,92 & 57,95 & 54,00 \\
\hline Guajará & 47,09 & 59,91 & 67,13 & 50,14 & 63,06 & 49,54 & 49,58 & 54,65 & 57,75 & 55,83 & 55,47 \\
\hline Pauini & 82,62 & 85,37 & 85,37 & 56,65 & 67,21 & 52,04 & 15,66 & 47,80 & 55,17 & 49,58 & 59,75 \\
\hline \multicolumn{12}{|c|}{ RORAIMA } \\
\hline \multicolumn{12}{|c|}{ Maior cobertura vacinal } \\
\hline Município & 2010 & 2011 & 2012 & 2013 & 2014 & 2015 & 2016 & 2017 & 2018 & 2019 & Méd \\
\hline Caroebe & 101,59 & 108,99 & 69,84 & 106,21 & 112,32 & 130,46 & 102,60 & 107,14 & 143,15 & 63,93 & 104,62 \\
\hline Mucajai & 105,05 & 87,21 & 99,66 & 77,35 & 262,59 & 69,91 & 76,92 & 101,67 & 58,47 & 65,37 & 100,42 \\
\hline Pacaraima & 81,47 & 85,31 & 62,24 & 49,83 & 79,82 & 93,48 & 118,05 & 99,70 & 118,82 & 153,42 & 94,21 \\
\hline Bonfim & 75,00 & 77,12 & 47,03 & 60,63 & 91,03 & 62,20 & 107,69 & 115,69 & 211,23 & 47,48 & 89,51 \\
\hline Boa vista & 92,69 & 98,00 & 91,27 & 79,83 & 82,82 & 105,12 & 93,25 & 97,87 & 68,63 & 80,46 & 88,99 \\
\hline \multicolumn{12}{|c|}{ Menor cobertura vacinal } \\
\hline Município & 2010 & 2011 & 2012 & 2013 & 2014 & 2015 & 2016 & 2017 & 2018 & 2019 & Méd \\
\hline Canta & 60,50 & 81,49 & 72,24 & 58,50 & 55,24 & 54,33 & 43,09 & 57,46 & 26,67 & 27,27 & 53,68 \\
\hline Amajari & 71,21 & 47,35 & 52,65 & 87,30 & 79,55 & 67,11 & 100,00 & 73,40 & 61,69 & 34,37 & 67,46 \\
\hline Uiramuta & 88,50 & 91,69 & 61,34 & 59,67 & 77,55 & 81,82 & 89,13 & 69,78 & 49,41 & 42,47 & 71,14 \\
\hline Normandia & 85,82 & 84,33 & 76,87 & 53,96 & 91,54 & 67,28 & 77,66 & 83,51 & 68,54 & 33,73 & 72,32 \\
\hline São Luiz & 84,62 & 100,00 & 34,07 & 92,13 & 70,24 & 51,25 & 71,64 & 131,34 & 103,61 & 27,36 & 76,63 \\
\hline
\end{tabular}




\begin{tabular}{|c|c|c|c|c|c|c|c|c|c|c|c|}
\hline \multicolumn{12}{|c|}{ PARÁ } \\
\hline \multicolumn{12}{|c|}{ Maior cobertura vacinal } \\
\hline Município & 2010 & 2011 & 2012 & 2013 & 2014 & 2015 & 2016 & 2017 & 2018 & 2019 & Méd \\
\hline Piçarra & 169,81 & 201,26 & 120,75 & 142,01 & 92,53 & 114,79 & 109,03 & 83,23 & 102,13 & 103,85 & 123,94 \\
\hline Santa Maria das Barreiras & 101,51 & 174,37 & 154,77 & 141,75 & 103,30 & 78,57 & 112,22 & 103,33 & 111,19 & 109,09 & 119,01 \\
\hline Bannach & 117,31 & 109,62 & 132,69 & 137,78 & 95,24 & 123,26 & 135,42 & 135,42 & 116,22 & 89,80 & 119,28 \\
\hline Ponta de pedras & 140,62 & 119,79 & 130,90 & 145,12 & 98,64 & 119,76 & 112,99 & 99,70 & 62,78 & 91,09 & 112,14 \\
\hline Sapucaia & 89,66 & 110,34 & 163,22 & 239,78 & 55,71 & 55,32 & 59,76 & 109,76 & 108,14 & 94,74 & 108,64 \\
\hline \multicolumn{12}{|c|}{ Menor cobertura vacinal } \\
\hline Município & 2010 & 2011 & 2012 & 2013 & 2014 & 2015 & 2016 & 2017 & 2018 & 2019 & Méd \\
\hline Afuá & 65,61 & 62,14 & 58,52 & 57,31 & 32,92 & 40,94 & 28,54 & 48,76 & 52,47 & 59,50 & 50,67 \\
\hline Chaves & 69,95 & 98,96 & 65,80 & 83,21 & 45,58 & 15,60 & 30,97 & 48,67 & 49,86 & 46,77 & 55,54 \\
\hline Melgaço & 54,60 & 63,18 & 71,29 & 80,59 & 53,07 & 36,23 & 39,55 & 47,26 & 54,18 & 62,99 & 56,29 \\
\hline Bagre & 80,46 & 77,47 & 82,99 & 99,16 & 32,54 & 47,56 & 51,95 & 30,98 & 38,21 & 67,45 & 60,88 \\
\hline Breves & 122,62 & 124,13 & 143,87 & 93,88 & 28,58 & 29,19 & 24,03 & 29,03 & 32,11 & 25,78 & 65,32 \\
\hline \multicolumn{12}{|c|}{ AMAPÁ } \\
\hline \multicolumn{12}{|c|}{ Maior cobertura vacinal } \\
\hline Município & 2010 & 2011 & 2012 & 2013 & 2014 & 2015 & 2016 & 2017 & 2018 & 2019 & Méd \\
\hline Cutias & 98,67 & 118,67 & 126,67 & 121,84 & 97,06 & 81,71 & 153,75 & 125,00 & 96,63 & 71,70 & 109,17 \\
\hline Calcoene & 96,19 & 105,71 & 107,62 & 144,50 & 57,22 & 67,18 & 69,07 & 75,26 & 97,16 & 124,76 & 94,47 \\
\hline Tartarugalzinho & 108,30 & 18,11 & 105,28 & 146,50 & 79,44 & 78,31 & 72,66 & 133,91 & 77,49 & 122,00 & 94,20 \\
\hline Serra do Navio & 101,35 & 93,24 & 122,97 & 120,00 & 24,68 & 38,64 & 32,88 & 191,78 & 108,96 & 125,00 & 95,95 \\
\hline Amapá & 101,65 & 121,49 & 87,60 & 81,29 & 81,08 & 93,51 & 98,58 & 61,70 & 90,91 & 122,70 & 94,05 \\
\hline \multicolumn{12}{|c|}{ Menor cobertura vacinal } \\
\hline Município & 2010 & 2011 & 2012 & 2013 & 2014 & 2015 & 2016 & 2017 & 2018 & 2019 & Méd \\
\hline Oiapoque & 132,87 & 45,79 & 57,87 & 30,43 & 41,12 & 47,31 & 41,67 & 53,79 & 53,23 & 45,96 & 55,00 \\
\hline Mazagão & 70,51 & 61,93 & 78,55 & 63,81 & 39,85 & 44,42 & 59,81 & 54,14 & 41,70 & 31,11 & 54,58 \\
\hline Pracuuba & 48,81 & 98,81 & 105,95 & 83,33 & 14,47 & 5,06 & 15,71 & 32,86 & 93,94 & 67,50 & 56,64 \\
\hline Itaubal & 94,81 & 100,00 & 88,31 & 47,96 & 48,04 & 21,74 & 41,53 & 50,00 & 69,39 & 78,33 & 64,01 \\
\hline Vitoria do Jari & 90,97 & 56,68 & 77,62 & 80,99 & 69,55 & 40,07 & 53,28 & 64,23 & 76,02 & 53,65 & 66,31 \\
\hline
\end{tabular}


TOCANTINS

\begin{tabular}{|c|c|c|c|c|c|c|c|c|c|c|c|}
\hline \multicolumn{12}{|c|}{ Maior cobertura vacinal } \\
\hline Município & 2010 & 2011 & 2012 & 2013 & 2014 & 2015 & 2016 & 2017 & 2018 & 2019 & Méd \\
\hline Talismã & 184,62 & 126,92 & 157,69 & 207,14 & 116,22 & 103,57 & 183,33 & 162,50 & 129,03 & 90,48 & 146,15 \\
\hline Lavandeira & 186,36 & 213,64 & 177,27 & 142,86 & 144,00 & 100,00 & 90,48 & 104,76 & 94,74 & 63,64 & 131,78 \\
\hline Brasilândia do Tocantins & 144,44 & 137,04 & 137,04 & 148,00 & 123,68 & 95,24 & 109,09 & 106,06 & 100,00 & 118,18 & 121,88 \\
\hline Campos Lindos & 188,64 & 136,36 & 114,39 & 132,47 & 91,41 & 122,60 & 89,76 & 89,16 & 94,00 & 122,70 & 118,15 \\
\hline Santa Rita do Tocantins & 104,00 & 88,00 & 156,00 & 131,82 & 100,00 & 131,82 & 107,69 & 100,00 & 133,33 & 106,90 & 115,96 \\
\hline \multicolumn{12}{|c|}{ Menor cobertura vacinal } \\
\hline Município & 2010 & 2011 & 2012 & 2013 & 2014 & 2015 & 2016 & 2017 & 2018 & 2019 & Méd \\
\hline Palmeirante & 63,33 & 58,89 & 61,11 & 88,00 & 69,12 & 64,15 & 68,00 & 78,00 & 70,77 & 36,62 & 65,80 \\
\hline Araguatins & 86,78 & 89,66 & 94,24 & 88,51 & 62,01 & 72,21 & 48,38 & 54,10 & 56,40 & 57,29 & 70,96 \\
\hline Augustinópolis & 70,03 & 94,68 & 89,08 & 47,92 & 62,46 & 45,77 & 77,51 & 73,67 & 78,48 & 85,90 & 72,55 \\
\hline Itaguatins & 70,53 & 60,00 & 71,58 & 114,63 & 66,28 & 69,39 & 60,76 & 67,09 & 88,41 & 50,00 & 71,87 \\
\hline Goiatins & 69,57 & 84,98 & 92,09 & 83,69 & 46,79 & 55,00 & 57,35 & 73,16 & 76,45 & 82,93 & 72,20 \\
\hline
\end{tabular}

Legenda: *Méd = Média.

Fonte: Gato AZS, et al., 2021, dados extraídos do site DATASUS, 2021. 


\section{DISCUSSÃO}

De acordo com o estudo de Alcântara AMAC, et al. (2020), os episódios de FA no Brasil após 1942 e, especialmente em 2017-2018, foram decorrentes do ciclo silvestre relacionados diretamente com a degradação e desastres ambientais. Os autores apontam que os casos de FA silvestre em humanos associados ao retorno do vetor urbano e as falhas nas coberturas vacinais convergem para uma ameaça de reurbanização dessa moléstia no país.

O Programa Nacional de Imunizações (PNI), do Brasil, fornece as vacinas devidas para a imunização de todas as faixas etárias e etnias presentes no país. Logo, está indicada a imunização contra febre amarela a partir de crianças de 9 meses que moram ou viajam para áreas endêmicas (Estados: AP, TO, MA MT, MS, RO, AC, RR, AM, PA, GO e DF), zonas de transição (alguns municípios de cada Estado: PI, BA, MG, SP, PR, $\mathrm{SC}$ e RS) e zonas de risco potencial (alguns municípios da BA, ES e MG). Todavia, apesar da distribuição da vacina pelo Sistema Único de Saúde (SUS), ainda existe um grande número de pessoas não vacinadas na região Norte (OLIVEIRA GS, et al., 2020).

Antes de tudo, é importante ressaltar que o reaparecimento de algumas doenças é causado por múltiplos fatores, uma vez que é impossível atrelar a volta de uma moléstia a apenas um fator específico. Sendo assim, o reaparecimento da febre amarela é multifatorial, com caráter ambiental, administrativo, coletivo e individual (OLIVEIRA GS, et al., 2020). Posto isso, no século atual, onde informações e notícias difundem-se cada vez mais rapidamente através dos meios digitais de comunicação, existe uma parcela delas que são inverídicas, pois são provenientes de fontes duvidosas e acabam causando impactos negativos na população. Assim, as informações falsas que circulam podem ser grandes responsáveis pelo número elevado de não vacinados na região Norte.

Nesse contexto, em 2018, observou-se um aumento na disseminação de notícias falsas sobre a FA, como o uso de própolis para espantar o mosquito causador da doença, receita para imunização contra a febre amarela com ingredientes naturais e até mesmo que um dos efeitos colaterais da vacina seria a meningite. Como resultado, neste mesmo ano, assim como observado no presente estudo, houve queda massiva no número de doses aplicadas e na cobertura da vacina contra a FA em quase toda a região Norte, onde apenas Pará e Amazonas mantiveram seus índices elevados; logo, podemos observar uma relação na queda desses fatores com a disseminação das fake news (TEIXEIRA A e SANTOS RCS, 2020).

Ademais, essa doença é de caráter sazonal, ou seja, em determinado período do ano tem seu "pico" e, segundo o Ministério da Saúde, esse fato está relacionado ao ciclo silvestre da doença, sendo esse um fator de gravidade (BRASIL, 2018). Consequentemente, isso é uma condição que pode intensificar o quadro de Febre Amarela, em toda a região Norte, em virtude que essas regiões apresentam uma alta pluviosidade, 0 que permite transmissão do vírus de forma mais alarmante (BRASIL, 2020a).

Desta forma, podemos constatar que essas áreas com altos índices pluviométricos têm maiores riscos de predispor um novo surto (BRASIL, 2020a). Diante disso, nos dados coletados, podemos enfatizar o estado de Tocantins, onde dos 5 municípios com pior cobertura vacinal analisados, 4 se localizavam nas proximidades da bacia hidrográfica do Tocantins-Araguaia, mostrando a fragilidade dessas regiões e como a qualquer instante podem predispor há novos surtos de FA. Somado a isso, vale-se destacar a questão de novas linhagens do vírus que aparecem a cada ano, tornando-se cada vez mais danosas às regiões com baixa cobertura vacinal (BRASIL, 2018).

Igualmente, outro dado que necessita ser evidenciado, é a cobertura vacinal e doses de vacinas aplicadas contra a FA no Estado do Pará, especialmente no Arquipélago do Marajó, que abrange quatro dos cinco municípios com os piores índices de vacinação da região. De acordo com as informações coletadas, podemos averiguar um decréscimo alarmante no decorrer dos anos, principalmente a partir de 2014, sobretudo no município de Breves, que apresentou a maior taxa exponencial de decréscimo. Ressalta-se que durante a disseminação da doença em 2008-2009 no Brasil, os primeiros casos foram observados no município, o que é preocupante uma vez que Breves é um local que costuma receber muitos visitantes e possui grande potencial turístico (MONATH TP e VASCONCELOS PFC, 2015; PARÁ, 2019). 
Posto isso, apesar da sua riqueza natural e cultural, a população da llha do Marajó é majoritariamente pobre e desassistida em todos os setores sociais; fato esse comprovado, após o Censo de 2010, do Instituto Brasileiro de Geografia estatística (IBGE), que trouxe um dos piores Índices de Desenvolvimento Humano (IDH) do país em oito de seus municípios, mostrando que os habitantes seguem expostos a um quadro de vulnerabilidade trágico. Somado a isso, essa região possui poucos investimentos de melhora nos setores básicos da população como, por exemplo, o de saúde onde os investimentos feitos foram majoritariamente inferiores os valores registrados em nível estadual e nacional, devido a uma dependência desse território de transferência de recursos da União e do Estado (BRASIL, 2020b).

Segundo a Organização Pan-Americana da Saúde (OPAS), nos últimos 3 anos houve uma expansão da área histórica de transmissão da febre amarela no Brasil (OPAS, 2018). Com efeito, no período 2014-2015, a transmissão que ocorreu inicialmente na região Norte expandiu-se de leste para sul, afetando principalmente os Estados da região Centro-Oeste em 2015-2016. No final de 2016 e até junho de 2017, foi registrado um surto de grandes proporções que afetou principalmente os Estados da região Sudeste com um total de 778 casos humanos, incluindo 262 óbitos e 1.655 epizootias por febre amarela. Os casos registrados em ambos os períodos, 2016-2017 e 2017-2018, superaram os casos notificados nos últimos 50 anos (OPAS, 2018).

De modo geral, este estudo evidenciou que tanto a cobertura vacinal quanto o número de doses aplicadas vêm caindo nos últimos dois anos em boa parte dos Estados da região Norte. Esse fato é preocupante, uma vez que o Norte se configura como uma região endêmica para a febre amarela e através da imunização, além do controle do mosquito, é possível garantir que, em casos de viajantes que visitam regiões como essa possam estar levando a doença para outros locais livres dela (BRASIL, 2018).

Em um estudo similar foi encontrado que, entre 2015 e 2019, a cobertura vacinal dos 9 imunobiológicos (BCG, Rotavírus Humano, Meningococo C, Hepatite B, Penta, Pneumocócica, Poliomielite, Febre Amarela e Hepatite A) analisados na região Norte foi de 79,20 , sendo assim a menor em comparação com as outras regiões do Brasil, enquanto a média nacional nesses anos foi de 85,36 (OLIVEIRA GS, et al., 2020).

Corroborando com os achados dos autores supramencionados, os Estados de Rondônia, Roraima e Tocantins foram os únicos que apresentaram cobertura vacinal média maior que 90 para a febre amarela e demais imunobiológicos (OLIVEIRA GS, et al., 2020). O teste Tukey comprovou a diferença entre o tamanho das amostras, confirmando que Rondônia é superior e diferente significativamente dos demais Estados quanto à cobertura vacinal.

Compreende-se que baixas na cobertura vacinal podem ser multifatoriais. Nesse sentido, considerando que os resultados desta pesquisa apontaram que o Pará, embora tenha se destacado quanto ao número de doses aplicadas, a cobertura vacinal foi uma das menores, especialmente entre 2015 e 2019. Diante disso, corroborando com Oliveira GS, et al. (2020), por ter a maior população entre os Estados da região Norte, com 7.581.051 habitantes, é possível que a população numerosa contribua com a baixa cobertura vacinal (IBGE, 2019).

Adicionalmente, outros fatores que influenciam os dados podem ser observados como, por exemplo, os próprios registros de cobertura vacinal, pois não é incomum que recém-nascidos sejam registrados em locais diferentes da residência da mãe, ou mesmo o acesso às salas de vacinação podem contribuir com alterações na cobertura vacinal de algumas regiões em virtude das alterações no cálculo da população-alvo (ARROYO LH, et al., 2020).

Ademais, questões estruturais contribuem com os resultados sobre cobertura vacinal, como a falta de cobertura de agentes comunitários de saúde (ACS), escassez de materiais e a própria hesitação vacinal, que pode ser motivada por aspectos sociais, emocionais, culturais, espirituais, cognitivos e até políticos (OLIVE JK, et al., 2018; SATO APS, 2018; SUCCI RCM, 2018; DUBÉ E, et al., 2015). Somado a isso, experiências pretéritas com os serviços de saúde, a forma como são veiculadas as informações sobre vacinação e, inclusive, o sucesso do programa de vacinação também influenciam os resultados (SUCCI RCM, 2018).

Outro agravante é o fato de que a população que foi vacinada na infância e atualmente não se depara com casos de FA, acaba não se dando conta dos riscos caso a imunização periódica não ocorra. Acredita-se que esses são os principais fatores que podem estar influenciando na diminuição da cobertura vacinal na região Norte. 
Totalizando 42 internações hospitalares e 2 óbitos por FA na região Norte registrados entre 2010 e 2019 , o Pará foi responsável pelo maior número de internações, com 10 no total, bem como para o número de óbitos, registrados no município de Santarém, localizado na região Oeste do Estado (PAULA A, et al., 2021). Corroborando com os autores, acredita-se que, em se tratando de uma região endêmica da doença, esses dados relativamente baixos podem contar com subnotificações. Similar aos resultados encontrados por Paula A, et al. (2021), os estudos de Cotta RO (2017) também verificaram maior número de óbitos e internações por FA na Região Sudeste, com destaque para o Estado de Minas Gerais, onde 61 municípios registraram óbitos e 224 notificações (SOUZA TS, et al., 2019).

Desse modo, a imunização vacinal torna-se a principal medida de controle da doença (BRASIL, 2018; NORONHA TG e CAMACHO LAB, 2017). Assim, os dados desta pesquisa mostraram que os municípios do Norte que mais vacinaram foram: São Francisco do Guaporé (RO); Plácido de Castro (AC); Careiro da Várzea (AM); Caroebe (RR); Piçarra (PA); Cutias (AP); e Talismã (TO). Por outro lado, os municípios que tiveram as menores médias de vacinação foram: Mirante da Serra (RO); Marechal Thaumaturgo (AC); Novo Aripuana (AM); Canta (RR); Afuá (PA); Mazagão (AP); e Palmeirante (TO).

Havendo a ocorrência de surtos, é recomenda a aplicação da vacina contra FA em toda a população não vacinadas anteriormente, bem como em pessoas que transitarão em áreas endêmicas da doença, ou seja, locais que representam maior risco de contaminação. Nesse sentido, a vacinação é exigida pelo Regulamento Sanitário Internacional para viajantes oriundos de áreas endêmicas ou com destino nesses locais (BRASIL, 2018). Nesse contexto, ressalta-se a importância da vigilância epidemiológica no combate à FA. Assim, com um esclarecimento maior sobre as principais características da FA na região Norte, as entidades responsáveis poderão estabelecer estratégias que visem aumentar a eficácia das políticas de combate à doença (PAULA A, et al., 2021).

O Ministério da Saúde recomenda que a vacinação seja priorizada aos grupos populacionais que representem maior risco, tais como pessoas que moram em áreas rurais ou silvestres, trabalhadores do ramo agropecuário, praticantes de ecoturismo, turismo de aventura ou turismo rural, especialmente viajantes que se deslocam para a área cuja recomendação de vacinação é permanente e/ou de risco (BRASIL, 2017; BRASIL, 2019).

Como estratégia, recomenda-se a expansão da cobertura vacinal a toda a população infantil, uma vez que esse grupo populacional é tido como de fácil acesso, em que não há relatos de importantes eventos adversos relacionados à vacinação, dentre outras questões favoráveis como a maior disponibilidade de vacina, além de terem maior possibilidade de avaliação adequada em casos de eventuais contraindicações (NORONHA TG e CAMACHO LAB, 2017).

Segundo Cavalcante KRLJ e Tauil PL (2017), uma medida a ser considerada para o combate à doença seria a implantação de unidades móveis de vacinação, principalmente em municípios em que ocorrem a transmissão silvestre da FA, isso poderia contribuir para um aumento na cobertura vacinal das populações mais vulneráveis à infecção, como a rural. Em síntese, com auxílio de ACS's, sugere-se um maior incremento nas buscas ativas, nas campanhas de vacinação e também na capacitação dos profissionais de saúde no reconhecimento dos riscos quanto a FA e na detecção das formas graves da doença.

\section{CONCLUSÃO}

Este estudo sinalizou a queda quanto a cobertura vacinal e número de doses aplicadas em vários Estados da região Norte no período de 2010 a 2019. As melhores médias de cobertura vacinal corresponderam ao Estado de Rondônia, enquanto o Pará se destacou com as melhores médias em relação ao número de doses aplicadas. Apesar disso, os últimos dois anos analisados tem revelado decréscimos na imunização contra FA, fato que precisa ser cuidadosamente investigado tanto pela literatura científica quanto pelas autoridades de saúde, uma vez que o Norte representa uma importante região de endemismo da doença. Os resultados encontrados contribuem com o desenvolvimento de estudos epidemiológicos sobre o assunto, bem como indica a necessidade de intensificação das medidas de prevenção voltadas para a vacinação da população como um todo na região Norte do país. 


\section{REFERÊNCIAS}

1. ALCÂNTARA AMAC, et al. Febre amarela: avanços e retrocessos desde as primeiras referências da doença às epidemias atuais. Revista Eletrônica Acervo Saúde, 2020; 38: e1834.

2. ARAÚJO MCG, et al. Fatores que interferem no cumprimento do calendário vacinal na infância. Revista Eletrônica Acervo Saúde, 2020; 42: e2874.

3. ARROYO LH, et al. Áreas com queda da cobertura vacinal para BCG, poliomielite e tríplice viral no Brasil (2006-2016): mapas da heterogeneidade regional. Cad Saúde Pública, 2020; 36(4): e00015619.

4. BARRETT ADT. Yellow fever in Angola and beyond: the problem of vaccine supply and demand. N Engl J Med 2016; 375: 301-03.

5. BRASIL. Manual de manejo clínico da febre amarela. 2020a. Disponível em: https://www.gov.br/saude/ptbr/media/pdf/2020/dezembro/03/manual_manejo_febre_amarela_3dez20_isbn.pdf. Acessado em: 14 de junho de 2021.

6. BRASIL. Programa Abrace o Marajó: Plano de Ação 2020-2023. 2020b. Disponível em: https://www.gov.br/mdh/ptbr/assuntos/noticias/2020-2/outubro/abrace-o-marajo-conheca-o-plano-de-acoes-do-programa-ate-

2023/19.10.2020VersoFINALPlanodeAcaoAbraceoMARAJO20202023.pdf. Acessado em: 14 de junho de 2021.

7. BRASIL. Guia de Vigilância em Saúde. 3a edição, volume único. 2019. Disponível em: http://portalarquivos2.saude.gov.br/images/pdf/2019/junho/25/guia-vigilancia-saudevolume-unico-3ed.pdf. Acessado em: 14 de junho de 2021.

8. BRASIL. Febre amarela: Guia para profissionais de saúde. 2018. Disponível em: https://portalarquivos2.saude.gov.br/images/pdf/2018/janeiro/18/Guia-febre-amarela-2018.pdf. Acessado em: 12 de junho de 2021.

9. BRASIL. Sociedade Brasileira de Infectologia. Febre amarela: informativo para profissionais de saúde. Brasil: SBI, 2017. Disponível em https://www.infectologia.org.br/admin/zcloud/125/2017/02/FA_Profissionais_13fev.pdf. Acessado em: 14 de junho de 2021.

10. CAVALCANTE KRLJ, TAUILPL. Risco de reintrodução da febre amarela urbana no Brasil. Epidemiol. Serv. Saude, 2017; 26(3): 617-620.

11. COTTA RO. Análise dos casos notificados de febre amarela no Brasil entre janeiro e maio de 2017. Trabalho de Conclusão de Curso (Especialização em Direito Sanitário) - Escola de Saúde Pública do Estado de Minas Gerais, Belo Horizonte, 2017; 24 p.

12. COUTO-LIMA D, et al. Potential risk of re-emergenceof urban transmission of Yellow Fever virus in Brazil facilitated by competent Aedes populations. Sci Rep, 2017; 7(4848): 1-12.

13. DUBE E, et al. Vaccine hesitancy, vaccine refusal and the anti-vaccine movement: influence, impact and implications. Expert Rev Vaccines, 2015;14(1): 99-117.

14. FIGUEIREDO PO, et al. Detection and Molecular Characterization of Yellow Fever Virus, 2017, Brazil. Ecohealth, 2018; 15(4): 864-870.

15. FOCACCIA R, VERONESI R. Tratado de Infectologia. 5nd ed. São Paulo: Atheneu, 2015; 427-465p.

16. INSTITUTO BRASILEIRO DE GEOGRAFIA E ESTATÍSTICA (IBGE). IBGE Cidades: Brasil/Pará. Diretoria de Pesquisas, Coordenação de População e Indicadores Sociais, Estimativas da população residente com data de referência $1 \stackrel{0}{\circ}$ de julho de 2019.

17. MCDONALD NE. Vaccine hesitancy: Definition, scope and determinants. Vaccine, 2015; 33(34): 4161-4164.

18. MIR D, et al. Phylodynamics of yellow fever virus in the Americas: new insights into the origin of the 2017 Brazilian outbreak. Scientific Reports, 2017; 7(7385): 1-9.

19. MONATH TP, VASCONCELOS PFC. Yellow fever. Journal of Clinical Virology, 2015; 64: 160-173.

20. NORONHA TG, CAMACHO LAB. Controvérsias sobre a ampliação das áreas com vacinação de rotina contra a febre amarela no Brasil. Cad. Saúde Pública, 2017; 33(10): e00060917.

21. OLIVE JK, et al. The state of the antivaccine movement in the United States: a focused examination of nonmedical exemptions in states and counties. PLoS Med, 2018; 15(6): e1002578.

22. OLIVEIRA GS, et al. Cobertura vacinal: uma análise comparativa entre os estados da Região Norte do Brasil. Revista de Patologia do Tocantins, 2020; 7(1): 14-17.

23. OPAS/OMS. Actualización Epidemiológica: Fiebre amarilla. $2018 . \quad$ Disponível em: https://iris.paho.org/bitstream/handle/10665.2/50544/Epiupdate7December2018_eng.pdf?sequence=1\&isAllowed=y. Acessado em: 14 junho de 2021.

24. PARÁ. Inventário da oferta turística do município de Breves - PA. 2019. Disponível em: http://www.setur.pa.gov.br/sites/default/files/iot_de_breves_concluido.pdf. Acessado em: 24 de junho de 2021.

25. PAULA, A, et al. Incidência e mortalidade da febre amarela no Estado do Pará. Brazilian Journal of Health Review, 2021; 4(3): 11538-11551.

26. POSSAS C, et al. Yellow fever outbreak in Brazil: the puzzle of rapid viral spread and challenges for immunisation. Mem. Inst. Oswaldo Cruz, 2018; 113(10): e180278.

27. SATO APS. Qual a importância da hesitação vacinal na queda das coberturas vacinais no Brasil?. Rev Saude Publica, 2018; 52(96): 1-9.

28. SOUZA TS, et al. Ocorrência de febre amarela no Brasil: uma revisão integrativa da literatura (2014-2018). Revista Eletrônica Acervo Saúde, 2019; 28: e896.

29. SUCCI RCM. Recusa vacinal - que é preciso saber. J Pediatr (Rio J); 2018; 94: 574-81.

30. TARTAGLIA TTS, PACCA, CC. Febre amarela no Brasil: da história ao risco de reemergencia. Revista De Medicina, 2019; 98(5): 334-340.

31. TEIXEIRA A, SANTOS RCS. Fake news colocam a vida em risco: a polêmica da campanha de vacinação contra a febre amarela no Brasil. Reciis - Rev Eletron Comun Inf Inov Saúde, 2020; 14(1): 72-89.

32. WORLD HEALTH ORGANIZATION (WHO). 2019. International travel and health. Estados Unidos da América: Geneva. Disponível em: https://www.who.int/ith/vaccines/yf/en/. Acessado em: 14 de junho de 2021. 